\title{
Pregnancy and neonatal outcomes in women with type 1 diabetes mellitus
}

\author{
Durackova L, Kristufkova A, Korbel M \\ 1st Department Gynaecology and Obstetrics, Medical Faculty, Comenius University, Bratislava, Slovakia. \\ lucia.federova@gmail.com
}

\begin{abstract}
AIM: The aim of study was to compare some perinatal outcomes in mothers with type 1 diabetes mellitus (T1DM). MATERIAL AND METHODS: All patients with T1DM delivered at the 1st Department of Obstetrics \& Gynaecology of Faculty of Medicine, Comenius University in Bratislava from January 1st 2009 to December 31th 2015 were included to the study.

RESULTS: Out of 118 diabetic mothers, $46.6 \%$ had vasculopathy and $53.4 \%$ were without microvascular complications. In the vasculopathy group, significantly higher incidence rates of preeclampsia (49. 1 versus $19.1 \% ; p=0.002$ ) and caesarean section (89.1 versus $68.3 \% ; p=0.017$ ) were found. Neonatal morbidity and mortality rates were higher in vasculopathy group (but not statistically significantly). Preparation for pregnancy improves perinatal and neonatal results. Nevertheless, this preparation in our study group was received only in $9.3 \%$. Perinatal mortality was 25.4 per 1,000 total births.

CONCLUSION: For pregnancy of diabetic women to become possible a qualified management must be provided. Good outcomes for both women and newborns are real when preparation for pregnancy and metabolic control before and during whole pregnancy are at adequate level (Tab. 3, Ref. 28). Text in PDF www.elis.sk. KEY WORDS: pregestational diabetes mellitus, perinatal outcomes, neonatal outcomes, vasculopathy, preparation for pregnancy.
\end{abstract}

\section{Introduction}

Diabetes mellitus (DM) is a disease of civilization, whose incidence recently reached pandemic character (1). Before the discovery of insulin, pregnancy in diabetic women was very rare and quite seldom brought to full-term live birth. About $60 \%$ of pregnant women were dying in severe ketoacidosis and more than $90 \%$ of infants were stillborn or died in the first hours after birth. Insulin has reduced mortality because of diabetic ketoacidosis reduction, improved fertility in diabetic women, but the perinatal mortality rate remained high (2).

A lot of diabetic women have vascular complications that significantly affect their quality of life and the definitive prognosis of the disease. The incidence of these complications in diabetic women in reproductive age is not rare. However, it is impossible to predict their extent, their impact on the course of pregnancy and vice versa, and the effect of pregnancy on further development of DM and diabetic complications (3).

Almost 30 years after Saint Vincent's Declaration, the neonatal morbidity and mortality rate remain high in diabetic women. In order to achieve perinatal outcomes comparable with general

1st Department Gynaecology and Obstetrics, Medical Faculty, Comenius University, Bratislava, Slovakia

Address for correspondence: L. Durackova, MD, Vinohradnicka 87, 90091 Limbach, Slovakia.

Phone: +421.903 932172 (non-diabetic) population, it is necessary to improve the preconception care and tight glycaemic controls throughout pregnancy and peripartal period. Good interdisciplinary cooperation (between diabetologist, obstetrician, neonatologist and other specialist) and management of these women in tertiary unit centres with neonatal intensive care units are very important, too.

\section{Materials and methods}

Women with type 1 diabetes mellitus (T1DM) who gave birth at the $1^{\text {st }}$ Department of Obstetrics and Gynaecology Faculty of Medicine, Comenius University in Bratislava (tertiary unit centre with neonatal intensive care unit) between 1st of January 2009 and 31st of December 2015, have been included in the study.

The study was designed to compare pregnancy and neonatal outcomes in women with T1DM without vasculopathy due to White's classification (classes B and C) and those with T1DM with vasculopathy (classes D, F, R and H) (4).

The comparison of pregnancy and neonatal outcomes in diabetic women with and without preparation for pregnancy was performed. Only singleton pregnancies were included into the study.

Maternal and foetal characteristics were extracted from the history and through hospital database system. Analysis of some demographic and perinatal indices (age of women, preconception care, preeclampsia-moderate and severe according to American College of Obstetrics and Gynaecologist-ACOG classification (5), modality of insulin treatment and metabolic compensation of dia- 
Tab. 1. Selected demographic data of women with T1DM.

\begin{tabular}{|c|c|c|}
\hline \multicolumn{2}{|l|}{ Characteristics } & $\begin{array}{l}\text { Women with } \\
\text { T1DM ( }=118)\end{array}$ \\
\hline \multicolumn{2}{|c|}{ Maternal age - mean (years) } & 29.28 \\
\hline \multicolumn{2}{|c|}{ Preparation for pregnancy (\%) } & 9.3 \\
\hline Preeclampsia (\%) & $\begin{array}{l}\text { Moderate } \\
\text { Severe }\end{array}$ & $\begin{array}{l}22.9 \\
10.2\end{array}$ \\
\hline $\begin{array}{l}\text { White‘s } \\
\text { classification (\%) }\end{array}$ & $\begin{array}{l}\text { Women with vasculopathy } \\
\text { Women without vasculopathy }\end{array}$ & $\begin{array}{c}46.6 \\
53.39 \\
\end{array}$ \\
\hline $\begin{array}{l}\text { Insulin treatment } \\
\text { modality (\%) }\end{array}$ & $\begin{array}{l}\text { IIT } \\
\text { CSII }\end{array}$ & $\begin{array}{l}52.5 \\
47.5\end{array}$ \\
\hline $\begin{array}{l}\text { Adequate metabolic } \\
\text { compensation (\%) }\end{array}$ & $\begin{array}{l}\text { Glycaemic level } \\
\text { HbA1c }\end{array}$ & $\begin{array}{l}17.8 \\
73.7 \\
\end{array}$ \\
\hline \multicolumn{2}{|c|}{ Gestational age at the time of delivery - mean (weeks) } & 36.45 \\
\hline $\begin{array}{l}\text { Mode of delivery } \\
\text { (\%) }\end{array}$ & $\begin{array}{l}\text { Vaginal } \\
\text { Caesarean section }\end{array}$ & $\begin{array}{l}22.0 \\
78.0\end{array}$ \\
\hline
\end{tabular}

T1DM - type 1diabetes mellitus, IIT - intensive insulin treatment, CSII - continuous subcutaneous insulin infusion (insulin pump), HbA1c - glycated haemoglobin A1c

betes during pregnancy, mode of delivery, gestational age and birth weight of infants) was done. Adequate metabolic compensation of DM was defined as glycaemic levels of 4-8 mmol/l and glycated haemoglobin A1c (HbA1c) according to Diabetes Control and Complications Trial (DCCT) level of 6.5-7.5 \% (3).

The primary neonatal outcomes were perinatal mortality and morbidity-premature labour before completed gestational week
37, perinatal asphyxia, congenital anomalies, macrosomia, foetal growth restriction, severe neonatal hypoglycaemia, hyperbilirubinemia, hypocalcaemia.

Perinatal mortality rate was defined as the number of stillbirths and deaths in the first week of life per 1,000 total births. Stillbirth (foetal mortality) was defined as birth of foetus without signs of life, weighing more than $1000 \mathrm{~g}$, or more than 28 weeks of gestation. Early neonatal mortality was defined as death of liveborn baby within the first seven days of life.

Macrosomia was defined as birth-weight higher than 90th percentile (large for gestational age-LGA) and foetal growth restriction as birth-weight lower than 10th percentile (small for gestational age-SGA) for infants (6).

Data analysis was performed by using descriptive statistics. The relationship between variables was performed using chi-square analysis or Fisher's exact test as appropriate, non-parametric Mann-Whitney's test and Kruskal-Wallis's test. $P$ values less than 0.05 were considered significant. The Statistical Package for the Social Science (SPSS) 19 was used.

\section{Results}

During the defined period, 118 women with T1DM were identified. Most of the women had diabetes of White's class C (30.5 \%) or B (22.9 \%), followed by D and F (18.6 \% each of them). A

Tab. 2. Pregnancy and neonatal outcomes in women without and with vasculopathy.

\begin{tabular}{|c|c|c|c|c|}
\hline Pregnancy and neonatal outcomes & & $\begin{array}{l}\text { Without vasculopathy } \\
\text { diabetic women } \\
n=63\end{array}$ & $\begin{array}{l}\text { With vasculopathy } \\
\text { diabetic women } \\
\mathrm{n}=55\end{array}$ & $\begin{array}{c}\text { Statistically significance } \\
\text { p }\end{array}$ \\
\hline $\begin{array}{l}\text { Gestational age at time } \\
\text { of delivery - mean week (range) }\end{array}$ & & $\begin{array}{c}36.67 \\
(25-40) \\
\end{array}$ & $\begin{array}{c}36.2 \\
(28-39) \\
\end{array}$ & NS \\
\hline Preeclampsia (\%) & $\begin{array}{l}\text { All together } \\
\text { Moderate } \\
\text { Severe }\end{array}$ & $\begin{array}{c}19.1 \\
14.3 \\
4.8\end{array}$ & $\begin{array}{l}49.1 \\
32.7 \\
16.4\end{array}$ & $\begin{array}{l}0.002 \\
\text { NS } \\
\text { NS }\end{array}$ \\
\hline Preterm birth (\%) & & 30.1 & 38.2 & NS \\
\hline Mode of delivery (\%) & $\begin{array}{l}\text { Vaginal } \\
\text { Caesarean section }\end{array}$ & $\begin{array}{l}31.7 \\
68.3 \\
\end{array}$ & $\begin{array}{l}10.9 \\
89.1\end{array}$ & $\begin{array}{l}0.017 \\
0.017\end{array}$ \\
\hline Birth weight of neonates (g) & $\begin{array}{l}\text { Mean } \\
\text { Range }\end{array}$ & $\begin{array}{c}3516 \\
870-5,060 \\
\end{array}$ & $\begin{array}{c}3376 \\
990-4,700 \\
\end{array}$ & $\begin{array}{l}\text { NS } \\
\text { NS }\end{array}$ \\
\hline Weight classification of neonates (\%) & $\begin{array}{l}\text { LGA } \\
\text { SGA } \\
\text { AGA }\end{array}$ & $\begin{array}{c}54.0 \\
4.76 \\
41.24 \\
\end{array}$ & $\begin{array}{c}63.6 \\
3.63 \\
32.77 \\
\end{array}$ & $\begin{array}{l}\text { NS } \\
\text { NS } \\
\text { NS }\end{array}$ \\
\hline Apgar score (mean) & $\begin{array}{l}\text { 1. } \min \\
5 . \min \\
\end{array}$ & $\begin{array}{c}7.79 \\
9\end{array}$ & $\begin{array}{c}7.85 \\
9\end{array}$ & $\begin{array}{l}\text { NS } \\
\text { NS }\end{array}$ \\
\hline Respiratory distress syndrome (\%) & & 17.5 & 30.9 & NS \\
\hline Hypoglycaemia (\%) & & 44.4 & 44.4 & NS \\
\hline Hypocalcaemia (\%) & & 14.3 & 5.5 & NS \\
\hline Hyperbilirubinaemia (\%) & & 36.5 & 21.8 & NS \\
\hline Congenital anomalies (\%) & $\begin{array}{l}\text { All together } \\
\text { Cardiac } \\
\text { Gastrointestinal }\end{array}$ & $\begin{array}{c}27.0 \\
27.0 \\
0\end{array}$ & $\begin{array}{c}32.8 \\
31.0 \\
1.8\end{array}$ & $\begin{array}{l}\text { NS } \\
\text { NS } \\
\text { NS }\end{array}$ \\
\hline Retinopathy of newborn (\%) & & 1.6 & 3.6 & NS \\
\hline Cataract of newborn (\%) & & 1.6 & 0 & NS \\
\hline Sepsis (\% of newborns) & & 4.8 & 1.8 & NS \\
\hline Perinatal mortality (per 1,000 total birth) & & 31,1 & 18,2 & NS \\
\hline
\end{tabular}


small part of women had T1DM of White's class R (7.6 \%) and $\mathrm{H}(1.7 \%)$. Selected demographic data of women and their infants are illustrated in Table 1.

There was a significantly higher incidence of preeclampsia in diabetic women with vasculopathy $(p=0.002)$ found. Moderate preeclampsia and severe preeclampsia have occurred in $32.7 \%$ and $16.4 \%$ of diabetic women with vasculopathy, respectively while in diabetic women without vasculopathy, the rates were $14.3 \%$ and $4.8 \%$, respectively.

There were statistically nonsignificant differences in gestational age and preterm birth in vasculopathy and non- vasculopathy groups of diabetic women ( $p=0.053$ ), but the range of gestational age at time of delivery was wider in women without vasculopathy than in those with vasculopathy (Tab. 2).

Caesarean section rate was statistically significantly higher in women with vasculopathy $(\mathrm{p}=0.017)$. Total vaginal delivery rate was three times and vaginal operative delivery rate was twice as high in group of women without vasculopathy (3.4\% versus $1.8 \%$ ).

The mean birth weight of newborns of diabetic women with vasculopathy was lower (median $3450 \mathrm{~g}$ ) than that of newborns of women without vasculopathy group (median 3,580 g). Nevertheless, macrosomia was more frequent in diabetic women with vasculopathy (63.6 \%) compared to women without vasculopathy ( $54 \%$; $\mathrm{p}=0.350$ ). The rate of SGA infants in both groups was almost the same (3.63 \% in group with vasculopathy versus $4.76 \%$ in that without vasculopathy).
Neonatal asphyxia was described by Apgar score (AS) at minutes 1 and 5 of life. There were no statistically significant differences between these two groups $(\mathrm{p}>0.05)$. Medians at minutes 1 and 5 were the same in both groups, namely 8 and 9 points, respectively. Only the range of AS was wider at minute 5 in the vasculopathy group ( $0-10$ versus $6-10$ points).

Frequency of respiratory distress syndrome was nearly twice as frequent in the group with vasculopathy, namely $30.9 \%$, compared to that without vasculopathy, namely $17.5 \%(p=0.087)$.

Severe neonatal hypoglycaemia was found equally often in both groups of women. Paradoxically, hyperbilirubinemia and hypocalcaemia were more frequent in women without vasculopathy.

Women with vasculopathy more often gave birth to infants with congenital anomalies, however this difference was not statistically significant; $p>0.05$. The most common anomalies were cardiac congenital anomalies (ventricular septal defect, patent ductus arteriosus), and those of gastrointestinal system.

Perinatal mortality per 1,000 total births in the study group of diabetic women was 25.4, stillbirths 8.5 and early neonatal mortality 16.9 .

One stillbirth has occurred in week 37 of gestation in a 29-year-old woman with vasculopathy (White class $\mathrm{D}$ ) because of intrauterine asphyxia. Two infants died in early neonatal period. One of them was born in gestation week 31 to a 32-year-old woman with vasculopathy and died 12 hours after delivery (because of diabetic cardiomyopathy). The second one was born in gestational week 34 to a 29-year-old woman without vascu-

Tab. 3. Pregnancy and neonatal outcomes in women with and without preparation for pregnancy of type 1 diabetes mellitus.

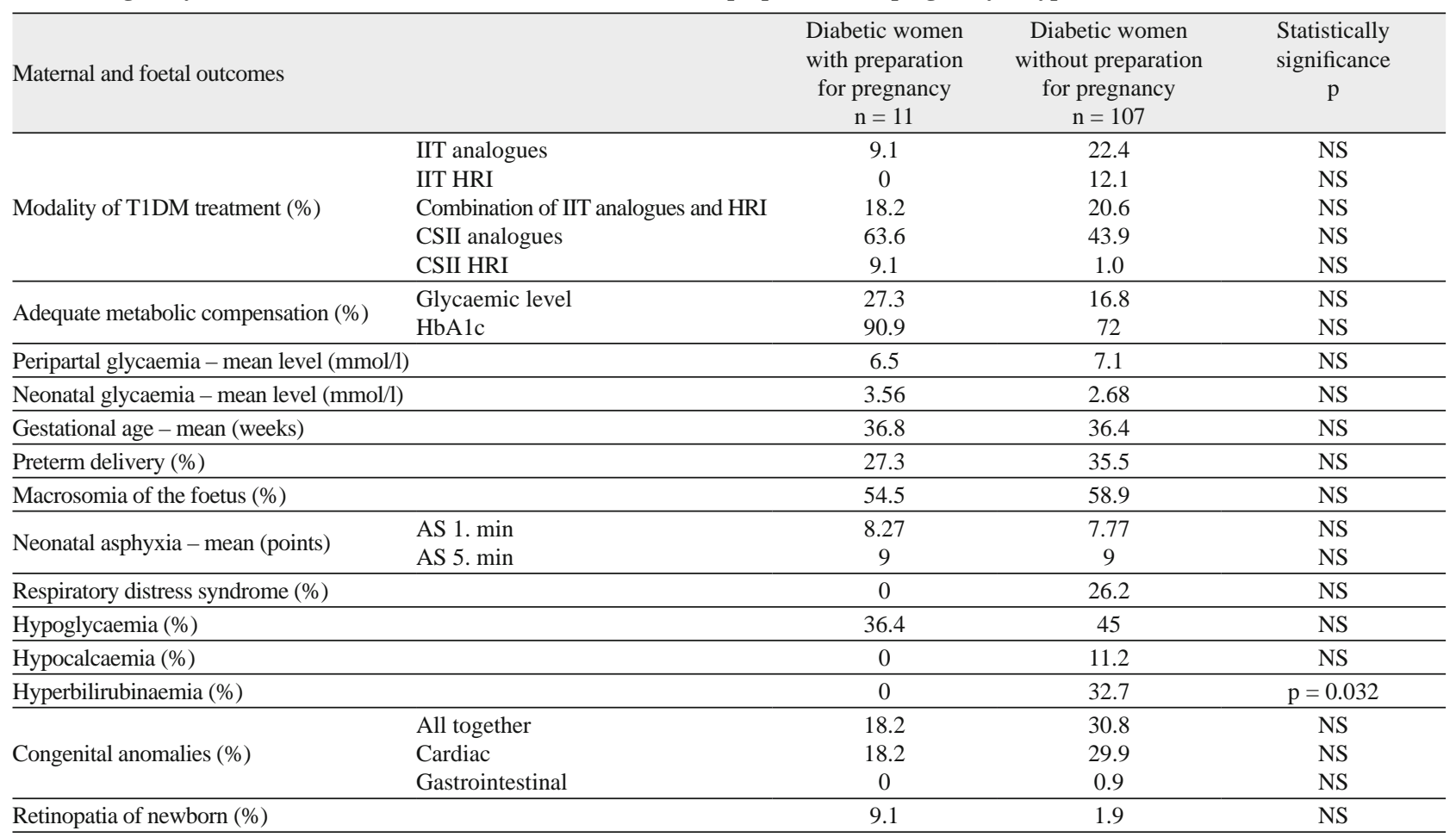

T1DM - type 1 diabetes mellitus, IIT - intensive insulin treatment, HRI - regular human insulin, CSII - continuous subcutaneous insulin infusion (insulin pump), AS - Apgar score, HbA1c - glycated haemoglobin A1c, NS - not significant statistically 
lopathy and died on day 4 of life (because of double outlet right ventricle).

Table 3 shows some perinatological data in diabetic women with and without preparation for pregnancy who gave birth during the defined period. Preparation for pregnancy of mothers with T1DM was insufficient, namely only $9.3 \%$ had preparation.

Metabolic compensation of diabetes during pregnancy was better in women with preparation for pregnancy (91 \% versus $72 \%)$, however the difference was not statistically significant $(p=0.066)$. The balance of blood glucose level in peripartal period was better in these women (range from 3.4 to $9.4 \mathrm{mmol} / \mathrm{l}$ ) than in those without preparation for pregnancy (range from 2.4 to 15.4 $\mathrm{mmol} / \mathrm{l}) ; \mathrm{p}=0.889$. Owing to better metabolic compensation in peripartal period, the infants of women with preparation for pregnancy had lower incidence of severe hypoglycaemia (36 \% versus $45 \%$ in women without preparation for pregnancy; $p=0.494$ ).

Women who were prepared for pregnancy gave premature birth less frequently (27. $3 \%$ ) compared to women without preparation (35.5\%; $\mathrm{p}=0.745)$.

All neonatal outcomes were better in women with preparation for pregnancy, even hyperbilirubinaemia was statistically significantly less frequent in these newborns ( $p=0.032)$.

Neonatal asphyxia was almost the same in both groups. Medians of Apgar score at minute 1 in women with and without preparation for pregnancy were 9 and 8 points, respectively. Median of AS at minute 5 was 9 points in both groups. There was a difference only in the range of AS: in women with preparation for pregnancy from 9 to 10 points and in women without preparation for pregnancy from 4 to10 points.

One stilllbirth was in a woman with preparation and two early neonatal deaths in women without preparation for pregnancy. Rate of congenital anomalies was $18.2 \%$ in women with preparation and almost twice as high (30.8 \%) in women without preparation for pregnancy $(\mathrm{p}=0.082)$.

\section{Discussion}

The incidence of T1DM in pregnancy during study period was $0.66 \%$. These findings are similar to the incidence data from other studies $(1,7,8)$. The incidence of pregestational diabetes births in Slovakia during study period was $0.27 \%$ (9).

The frequency of hypertension in pregnancy and preeclampsia in diabetic women is 2 to 4 times more frequent than in non-diabetic population $(3,10)$. In our study, frequency of preeclampsia was $33 \%$, which is almost 3 times more frequent than reported $12 \%$ in other studies $(11,12)$.

The incidence of premature labour during the study period was $33.9 \%$. Similar data were reported by Melamed et al (13).

Women with T1DM have higher rates of caesarean section in general. Its frequency throughout the world is about $60 \%(14$, $15)$, and the highest one is reported in Italy (73\%) (16). The frequency of caesarean section in our department during study period was $78 \%$, but in the years 1994-2000 it was only $37.2 \%$ (17). This frequency is determined by higher frequency of cephalopelvic disproportion caused by macrosomia of the foetus (58.5\%), worsening symptoms of preeclampsia (33\%) and incidence of repeated caesarean sections too.

The more complicated course of pregnancy itself and perinatal outcomes are expected more in diabetic women with vasculopathy than in those without vasculopathy (18). Women with advanced diabetic microvascular complications (White class $\mathrm{D}, \mathrm{F}$ and $\mathrm{R}$ ) often delivered SGA infants. This situation is exacerbated by the fact, that most of these pregnancies are terminated prematurely because of worsened preeclampsia (19). In our presented study, the frequency of SGA infants in diabetic women with vasculopathy was almost the same (3.63\%) as in those without vasculopathy (4.76\%). Paradoxically, there was even a higher incidence of macrosomic infants in diabetic women with vasculopathy compared to those without vasculopathy (63.6 \% vs $54 \%$ ). Our observations are in contrast with the results of Salafia et al. and Haeri et al, who reported that the vasculopathy-induced damage of organs manifested in foetal growth restriction. This hypothesis is based on the fact that diabetic microangiopathy changes impair the foetal-placental flow stream and thus the delivery of nutrients to the foetus becomes impaired as well $(20,21)$. In our study group, we have confirmed worse neonatal outcomes (preterm labour, neonatal asphyxia, respiratory distress syndrome, frequency of congenital cardiac and gastrointestinal anomalies, retinopathy) in women with vasculopathy.

The coincidence of diabetes mellitus and pregnancy predisposes the mother and foetus to a lot of serious risks. It is therefore necessary to plan pregnancy to the period of optimum metabolic compensation of DM. Preparation for pregnancy of diabetic women should start at months 3-6 before planned conception (3, $22,23)$. More than two-thirds of diabetic women in many countries start their pregnancy without preparation $(19,24,25)$. The incidence of preparation for pregnancy in our study was only 9.3 $\%$, which is a very insufficient rate. The expected importance of preparation for pregnancy in our study was confirmed almost in all outcomes but the statistical significance was not reached in all. This fact was caused by a small number of patients with preparation for pregnancy. Out of these women with preparation for pregnancy, only $27.3 \%$ were optimally prepared (preparation lasting 3-6 months with optimal metabolic compensation of DM). The blood glucose level range was in adequate levels in almost $30 \%$ of diabetic women with preparation for pregnancy versus $16.8 \%$ of women without preparation for pregnancy. Diabetic women with preparation for pregnancy yielded adequate level of HbA1c range in $91 \%$ versus $72 \%$ yielded by those without preparation. These statements lead also to balanced peripartal glycaemic levels. This implies a lower frequency of severe hypoglycaemia in their infants (1).

Good metabolic control before and in early pregnancy is a prerequisite for prevention of progression of diabetic embryopathy (3, 24). The incidence of congenital anomalies in infants of diabetic women is $4-10$ times higher than that in non-diabetic population. It depends on metabolic compensation of $\operatorname{DM}(3,14,25,26)$. This fact was also demonstrated in our study, where in diabetic women with preparation for pregnancy, the frequency of congenital cardiac anomalies was $18 \%$, whereas in those without preparation for preg- 
nancy, it was $30 \%$. This high frequency of congenital anomalies in women with preconceptional preparation in our study is caused by poor quality of this preparation for pregnancy.

\section{Conclusion}

Pregnancy represents a high risk for diabetic women. In most cases, it can be possible and real if qualified management is provided. In such cases, successful pregnancy outcomes for both women and infants can be expected, and perinatal results comparable with general non-diabetic population can be achieved, or even better $(22,25,27,28)$.

In Slovakia, it is still necessary to improve the preparation for pregnancy in diabetic women and their metabolic control during pregnancy. Should this be achieved, the rate of major congenital anomalies and caesarean sections could be reduced in this population.

\section{References}

1. Tennant PWG, Glinianaia SV, Bilous RW et al. Pre-existing diabetes, maternal glycated haemoglobin, and the risks of fetal and infant death: a population-based study. Diabetologia 2014; 57 (2): 285-294.

2. Vargas R, Repke JT, Ural SH. Type 1 Diabetes Mellitus and Pregnancy. Rev Obstet Gynecol 2010; 3 (3): 92-100.

3. American Diabetes Association. Standards of medical care in Diabetes-2015. Diabetes Care 2015; 38 (1): S 1-S 93.

4. White P. Classification of obstetric diabetes. Am J Obstet Gynecol 1978; 130 (2): 228-230.

5. Task Force Report on Hypertension in Pregnancy by The American College of Obstetricions and Gynecologist. Hypertension in pregnancy. Washington, DC: ACOG publishing, 2013: 1-100.

6. Xu H, Simonet F, Luo ZC. Optimal birth weight percetnil cut-offs in defining small- or large-for-gestational age. Acta Paediatr 2010; 99 (3): 550-555.

7. Lepercq J. Pre-existing diabetes and pregnancy. Rev Prat 2012; 62 (7): 917-920.

8. Lawrence JM, Contreras R, Chen $\mathbf{W}$ et al. Trends in the prevalence of preexisting diabetes and gestational diabetes mellitus among a racially/ ethnically diverse population of pregnant women, 1999-2005. Diabetes Care 2008; 31 (5): 899-940.

9. Korbel M. Diabetes mellitus and pregnancy. Gynekol Prax 2005; 3 (2): 79-80.

10. Weissgerber TL, Mudd LM. Preeclampsia and diabetes. Curr Diab Rep 2015; 15 (3): 9-14.

11. Temple RC, Aldridge V, Stanley K et al. Glycaemic control throughout pregnancy and risk of pre-eclampsia in women with type I diabetes. BJOG 2006; 113 (2): 1329-1332.
12. Cohen AL, Wenger JB, James-Todd T et al. The association of circulating angiogenic factors and $\mathrm{HbA} 1 \mathrm{c}$ with the risk of preeclampsia in women with preexisting diabetes. Hypertens Pregnancy 2014; 33 (1): 81-92.

13. Melamed N, Chen R, Soiberman U et al. Spontaneous and indicated preterm delivery in pregestational diabetes mellitus: etiology and risk factors. Arch Gynecol Obstet 2008; 278 (2): 129-134.

14. Negrato L et al. Adverse pregnancy outcomes in women with diabetes. Diabet Metab Syndr 2012; 4 (1): 41-45.

15. Hod M, Mathiesen ER, Jovanovic $L$ et al. A randomized trial comparing perinatal outcomes using detemir or neutral protamine Hagedorn in type 1 diabetes. J Matern Fetal Neonatal Med 2014; 27 (1): 7-13.

16. Lapolla A, Dalfra MG, Romoli E et al. Use of insulin lispro protamine suspension in pregnancy. Adv Ther 2015; 32 (10): 888-905.

17. Havalda A. Doppler ultrasound of fetoplacental circulation in monitoring of foetal well-being diabetic mothers in 3rd trimester of pregnancy. PhD work. Bratislava: Comenius University Faculty of Medicine Bratislava, 2001: 1-114.

18. Leguizamón G, Trigubo D, Pereira JI et al. Vascular complications in the diabetic pregnancy. Curr Diab Rep 2015; 15 (1): 22-32.

19. Toserová E. Diabetes mellitus type 1 and 2 - diabetologic management. Gynekol Prax 2005; 3 (2): 84-89.

20. Salafia CM, Charles AK. Diabetes and related metabolic states and the placenta. 68-88. In: Langer O. The diabetes in pregnancy dilemma. Lanham: University Press of America, 2006.

21. Haeri S, Khoury J, Kovilam $\mathbf{O}$ et al. The association of intrauterine growth abnormalities in women with type 1 diabetes mellitus complicated by vasculopathy. Am J Obstet Gynecol 2008; 199 (3): 278-281.

22. Korbel M, Borovsky M, Danko J et al. Analysis of maternal morbidity in Slovak Republic in the year 2014. Gynekol Prax 2016; 14 (2): 66-72.

23. Egan AM, Smith V, Devane D et al. Effectiveness of prepregnancy care for women with pregestational diabetes mellitus: protocol for systematic review of the literature and identification of a core outcomes set using a Delphi survey. Trials 2015; 356 (16): 1-7.

24. Bond S. Universal Preconception Care Could Improve Maternal and Decrease Economic Costs of Pregestational Diabetes. J Midwifery \& Women's Health 2015; 60 (3): 332-334.

25. McCance DR. Diabetes in pregnancy. Best Pract Res Clin Obstet Gynaecol 2015; 29 (5): 685-699.

26. Feig DS, Hwee J, Shah BR et al. Trends in Incidence of Diabetes in Pregnancy and Serious Perinatal Outcomes: A Large, PopulationBased Study in Ontario, Canada, 1996-2010. Diabetes Care 2014; 37 (3):1590-1596.

27. Mathiesen ER, Ringholm L, Damm P. Pregnancy management of women with pregestational diabetes. Endocrinol Metab Clin North Am 2011; 40 (4): 727-738.

28. Ballas J, Moore TR, Ramos GA. Management of diabetes in pregnancy. Curr Diab Rep 2012; 12 (1): 33-42.

Received September 20, 2016. Accepted October 12, 2016. 